\title{
Expectations of Industry from Technical Graduates: Implications for Curriculum and Instructional Processes
}

\author{
P. K. Tulsi \\ Dean R\&D and Prof. \& Head \\ Education \& Educational Management Department, NITTTR, \\ Sector 26, Chandigarh-160019 \\ e-mail:pk_tulsi@yahoo.com
}

\author{
M. P. Poonia \\ National Institute of Technical Teachers' Training \& Research, \\ Chandigarh, India \\ e-mail:director@nitttrchd.ac.in
}

\begin{abstract}
Industry is operating in an environment characterized by high performance work culture, intense competition, emphasis on quality, value addition, diversification of products and services, and automation as a result of globalization. Industry requires job ready graduates. It has been found that (a) the employability of technical graduates is low, (b) the requirements of skill set vary from sector to sector, (C) technical knowledge and skills are considered to be important but soft skills (communication skills, self discipline, team work, willingness to learn, flexibility, creativity etc.) are considered to be more important for employability, (d) technical graduates lack higher order cognitive skills such as ability to analyze, logical reasoning, ability to evaluate and create, and ability to solve problems, (e) knowledge of computers and mathematics are essential for an engineer to succeed, and (f) teaching-learning processes must focus on higher order thinking skills, problem solving and creativity and evaluation processes must change accordingly. Technical education needs total revamping and changes need to be introduced in the various sub-components of the system. The paper deals with the strategies that can be used to improve the quality of curriculum and instructional processes, and collaboration with industry.
\end{abstract}

Keywords-Technical graduates, Industry, Curriculum and Instructional Processes.

\section{P. K. Tulsi}

Dean R\&D and Prof. \& Head

Education \& Educational Management Department, NITTTR, Sector 26, Chandigarh-160019

e-mail: pk tulsi@yahoo.com

\section{Introduction}

The acceptability of graduates from technical or engineering education institutions is a cause of concern world over. According to the results of 2013 Talent Shortage survey [1], the most acute talent shortages are reported in Japan (85\%) and Brazil (68\%). The problem is widespread in Asia Pacific, with more than half the employers surveyed in India (61\%), Hong Kong (57\%) and New Zealand (51\%) saying that talent shortages prevent them from hiring people with needed skills. Industry is operating in an environment characterized by high performance work culture, intense competition, greater emphasis on quality or value addition, diversification of products and services, and automation as a result of globalization. Industry requires job ready graduates who possess the requisite competencies and can take up the assigned projects or tasks. The competencies expected of graduates include not only technical knowledge and skills but also ability to work in teams, leadership, interpersonal skills, communication, creativity and adaptability. Industry is facing shortage of competent trained manpower and need to spend time, money and resources to train manpower to make them job ready. The situation calls forth for a closer collaboration between the technical institutes and industry. Though changes are required in various subcomponents of the technical education system, but 
two of the sub-components - curriculum and instructional processes need urgent attention to produce job ready graduates.

\section{Technical Education in India}

The country has third largest system of education in place. Technical education in India comprises of 81 centrally funded institutions, 8562 degree level institutions and 3524 diploma level approved institutions with an intake capacity of 3.4 million [2]. Technical manpower, trained by the system, in turn contributes to economic growth and development of a country. During the last two decades, there has been tremendous increase in the number of technical institutions but still there is a scope for expansion of technical institutions as the Gross Enrolment Ratio (GER) at higher and technical education level is only $22 \%$. Govt. of India has set a target of achieving $30 \%$ enrolment by the year 2020 . The quality of technical education is under severe criticism and is of concern to all stakeholders namely policy makers, administrators, teachers, students, industry and society. One of the parameters of measuring quality has been the employability of graduates from these technical institutions. There are two views on employability-a narrow view and a broader view. When viewed in narrow sense, it simply refers to as to how many students get employed on completion of the programme from the institution. But in broadest sense it refers to how successfully a person is able to manage his career and lead a productive and meaningful life. Most of the surveys or studies undertaken in the area have taken the narrow viewpoint of employability.

\section{Employability Of Graduates: R e v i e w of Relevant Literature}

A survey conducted by NASSCOM and McKinsey Global Institute in 2005 reported that India produced 0.36 million engineering graduates and 0.6 million other graduates in arts, science and commerce. It was found that only $25 \%$ of the engineering graduates and $10 \%$ of other graduates were employable.

Aspiring Minds Computer Aptitude Test (AMCAT) was conducted for .04 million students of engineering and Master's in Computer Application (final year) across the country in twelve states [3]. AMCAT covers all objective parameters for adjudging employability in the IT/ITeS sector including English communication, Quantitative skills, Problem solving skills, and Computer science and Programming skills. The study findings suggested that employability varied from sector to sector. The percentage of students found fit to be employable in IT product sector, Knowledge Process Outsourcing (KPO), Tech Support, and in BPO sector were $4.2 \%$, $9.5 \%, 25.9 \%$, and $38.2 \%$ respectively. The study suggested that to enhance employability in IT product sector, the emphasis in technical institutions should be on product development and research while in case of BPO and Tech Support sector, the institutions should focus on developing soft skills and problem solving skills.

The results of a case study of employability of engineering graduates revealed that the performance of students in non-technical education (verbal reasoning, logical reasoning and soft skills) was a strong predictor of employability than was the grade obtained in technical education [4]. In another study, it was found that knowledge of Engineering (Grade Point Average) and proficiency in English language were important predictors of continuous employability of engineering graduates in campus interviews of software services companies [5].

Employer satisfaction survey was conducted by an education team of South Asia Region, World Bank[6]. One hundred and fifty seven employers across sectors and regions in India completed the on-line questionnaire. The study led to the identification of three sets of factors namely core employability skills, professional skills and communication skills that affect the employability of graduates from technical institutions. Core employability skills comprised of integrity, self discipline, reliability, self motivated, entrepreneurial skills, team work, understand and take direction for work assignments, willingness to learn, flexibility and empathy. Professional skills consisted of identify, formulate and solve technical and engineering problems, design a system, component or process to meet desired needs, use appropriate modern tools, equipment, technologies, apply knowledge of mathematics, science and engineering, customer service skills, knowledge of contemporary issues and creativity. Communication skills included written communication, design \& conduct of experiments, \& analyze and interpret data, reading, communication in English, technical skills, verbal communication, basic computer and advanced computer. Employers rated core employability skills (4.27) more important than the professional skills (3.91) and communication skills (4.01). Soft skills (core employability skills and 
communication skills) were rated significantly more important than the professional skills. Employers are less than 'somewhat satisfied' with these skills. Further, these higher-order thinking skills were considered the most important Professional Skills. The findings suggested that engineering education institutions should recognize the importance of Soft Skills and refocus the assessments, teaching-learning process, and curricula away from lower-order thinking skills, such as remembering and understanding, toward higher-order skills, such as analyzing and solving engineering problems, as well as creativity.

A review of evidence on best practice in teaching and assessing employability skills concluded that the major pedagogical approaches used in relation to employability-relevant skills do tend toward experiential and action learning methods in all the settings [7]. In higher education, games and again work placements or group projects might be used to support more traditional practices. There tends to be a greater emphasis on blending assessment techniques to include coursework and evidence portfolios to document the learners' abilities and skills which might have been demonstrated in a work or project-based environment

From the studies described above, it can be concluded that (a) the employability of technical graduates is low, (b) the requirements of skill set vary from sector to sector, (c) technical knowledge and skills are considered to be important but soft skills (communication skills, self discipline, team work, willingness to learn, flexibility, creativity etc.) are considered to be more important for employability, (d) technical graduates lack higher order cognitive skills such as ability to analyze, logical reasoning, ability to evaluate and create, and ability to solve problems, (e) knowledge of computers and mathematics are essentialfor an engineer to succeed, (f) teachinglearning processes must focus on higher order thinking skills, problem solving and creativity and evaluation processes must change accordingly.

\section{Panel Discussions Organized by NITTR}

National Institute of Technical Teachers' Training and Research (NITTTR), Chandigarh, since its inception in 1967, has been in the service of technical education especially in the northern region of the country. The institution was set up with a mandate to improve the quality of technical education. Ministry of Human Resource Development (MHRD), Government of India (GOI), in the year 2012, gave a mandate to the institute to train 20,000 teachers through Induction Training Programmes in order to improve quality of faculty and in turn the quality of instruction in technical institutions. Thus, the institute ventured into designing and offering teacher training programmes through integration of information and communication technologies. Panel discussion on the theme 'Expectations of Industry from the Technical Graduates' was made an integral part of the Induction Training Programme with the objectives (a) to identify the skill gaps that exist and (b) seek suggestions from the industry personnel and academia to bridge the gap by introducing needed changes in the technical education system. Forty-three panel discussions have been organized till date. Panelists included the industry personnel from a wide variety of industries such as manufacturing, construction, pharmaceutical, electronics, automobile, infrastructure, bio- technology, service etc. Some of the major issues that emerged included:

\section{Students}

- lack fundamental knowledge of terminology, concepts, principles etc. in their own disciplines

- lack knowledge of current developments in their disciplines and technology

- lack practical skills

- are unable to read engineering drawings

- lack analytical ability, ability to work in teams, willingness to learn, communication skills, managerial skills and creativity

- lack positive attitude and have become more materialistic

- prefer to look for white collar jobs and prefer to work in IT or ITeS sector and do not continue in the core engineering branches

- lack commitment and stability

The panelist suggested that:

- The system of technical education needs total revamping

- Changes need to be introduced from time to time in the curriculum of various courses for enhancing relevance

- Curriculum must reflect the needs of small scale industries too

- Instructional methods such as seminar, group discussion, brainstorming, collaborative project work, and case study should be used to develop higher order cognitive abilities and also soft skills among students 
- Emphasis should be on group tasks/activities

- Practical work, as per the curricular requirements, must be accomplished

- Laboratories and workshops must be strengthened to provide adequate practical training to students and instill confidence among them

- Teachers should acquire proficiency in handling practical work and should facilitate the acquisition of skills by the students

- Projects should be live problems from the industry or the society

- There is a need to develop ethics and values

- There should be closer collaboration between industry and academia is required

Both the review of relevant literature and the panel discussions clearly point towards the skill gap that exist between the requirements of the industry and the skill set being developed among the technical graduates. There is a need to develop curricula as per the requirement of industry and create a conducive environment in technical institutions for quality instruction (both theory and practical) to develop the required competencies among technical graduates.

\section{Strategies for Improving Curriculum and Instructional Processes}

The strategies that can be used to develop relevant curriculum for various courses and improving quality of instruction have been discussed in the following paragraphs.

5.1 Implications for Curriculum:

Major changes required in curricula of various courses include:

- All curricula should be aligned to graduate attributes enlisted by American Board of Engineering \& Technology (ABET) and accepted by the countries signing Washington accord.

- All curricula should be designed on a modular pattern with credit-based system of evaluation in order to provide flexibility and allow self-pacing to the learners.

- A number of specializations need to be introduced in each discipline so as to enable the students to select courses as per their interests. There may be provision for core courses and open electives. Open electives should be offered at higher level. Before offering open electives, all core courses must be learnt.

- Innovative approaches in design of curriculum can be used to provide enriched experiences to students. For example, a three semester corse on engineering design -Design Tools, Design Process and Design experiences, has been included in the curriculum of Electrical Engineering to provide more hands-on design into the curriculum [8]. College of Engineering, University of Texas (UTSA) has seen measurable improvements in the retention rate and grade point average of students who participated in a freshman seminar course called Just in Time Math (JTM). The Just in Time Math seminar course exposes first-year students to lab experience and math topics most heavily used in core engineering courses such as statics, dynamics and electrical circuits [9].

- Courses related to humanities \& social sciences, management, professional ethics \& values, environmental engineering, sustainable development, engineering and project management[10] need to be included in curriculum.

- Emerging technologies such as Body adapted Wearables Electronics, Nanostructured Carbon Composites, Mining Metals from Desalination Brine, Grid-scale Electrical Storage, Nanowire Lithium-ion Batteries, Screenless Displays, Human Microbiome Therapeutics, RNA-based Therapeutics, Quantified Self (predictive Analytics), and Brain Computer Interfaces[11] should be included in the relevant disciplines.

- Soft skills such as communication, creativity, leadership, working in teams, interpersonal skills, life long learning must find a place in the curriculum of various courses

- There should also be provision for auditing of courses.

- A variety of modes of offering the programmes such as regular contact mode, distance education, open learning etc. should be used to meet the diverse needs of the clientele (regular students, working personnel, disadvantaged groups etc.) and increasing access of technical education.

- Curricula need to be revised and modified more frequently on the basis of systematic feedback from students, teachers, pass-out students and industry/other work organizations

- Industry involvement needs to ensured in curriculum design process to make it relevant and appropriate to the needs of the world of work and also to enhance employability of graduates.

\subsection{Implications for Instructional Processes}

Changes need to be introduced in the instructional processes and evaluation processes to develop the 
necessary practical skills (hands on), higher order cognitive abilities (Minds on), and sensitizing the students to needs of society (hearts on,) and in turn to enhance the employability of technical graduates [12].

\subsection{Strategies for Hands on}

- Plan as to what is to be learnt by students, allow students to explore, provide adequate practice to learners and then allow them to perform (PlanExplore-Practice-Perform) [13].

- Project work-both minor and major should be included to help students to apply the learnt knowledge and skills to find solution to problems.

- Structured industrial training at least for six months in the last semester or in a phased manner over a period of last two years should be provided to students. A workbook comprising of questions related to various aspects of industryorganizational structures, processes, products, technology, problems, application of learnt concepts, principles, procedures etc need to be designed.

- An alternate strategy can be used for providing hands on experience to students. During the first year, students should be encouraged to look for appliances/gadgets related to their disciplines available at home and get familiarized with those. In second year, students are to be encouraged to work under the supervision of teachers and technicians in the laboratories. During third year, training under the skilled person/master craftsman in the vicinity needs to be organized and during fourth year of training, socially relevant projects or industrial projects are to be undertaken by students.

- Practical work should results in a useful product that is saleable in the market. For example, students of mechanical engineering in workshop may design furniture which teaches them various types of joints, manufacturing techniques, selection of material, selection of tools, economics etc.

- Students should have open access to laboratories and workshops for experimentation. This will instill confidence among students, develop research culture and may also lead to new designs, techniques, processes etc.

- Faculty undertaking sponsored research and consultancy projects should involve students in their projects. Students can thus be groomed for research.
- Competitions can be organized for students to motivate them to take up novel and challenging projects and find innovative solutions to the problems. Again, multi-disciplinary teams can be constituted to promote cross-fertilization of ideas and promote multi-disciplinary research.

- The laboratories and workshops need to be modernized as per the latest trends in the various disciplines to provide industry like environment to students. Institutions in the vicinity can think of establishing joint laboratories in order to ensure optimum utilization of resources.

- Industry-Academia exchange programmes can help in providing required industrial exposure to faculty and also help the students to get practical knowledge from the industry personnel. In addition, industry personnel can be invited to interact with the faculty and students from time to time and they can be involved in curriculum design process.

\subsubsection{Strategies for Minds on}

- Instructional methods such as Case studies, Problem- solving, Problem based learning, Projects, Group Discussion and Brainstorming should be introduced in order to involve students actively in classrooms. These instructional methods will help the students to develop analytical ability, ability to apply learnt concepts and principles in solving a problem and generate solutions to problems. This will also give them an opportunity to work in teams and generate interaction among the students.

- In theory classes, students should be encouraged to take up minor projects such as surveying the market, collecting information about the technology, machines, products and materials, compare the gathered information on various parameters, share information with other students and make presentations in the class.

- Peer learning opportunities, where good students can teach other students, need to be provided to students. Students may be paired or grouped in such a manner that a good student is able to help others in their learning. Peer learning results in higher learning as students are able to freely exchange the information and clarify their doubts.

- Teachers need to provide experiences to students where by they can observe a phenomenon or a process and then questions related to why and how can be raised to develop ability to observe, analyze and apply learnt knowledge. In simple words, 
content need to be organized from observation to reasoning.

- In order to develop creativity among students, students should be encouraged to experiment with new ideas, techniques, models etc. Brainstorming, attribute listing analogies, and metaphors can be used in classroom teaching. Problems that can have multiple right answers need to be assigned to students to allow them think of alternate solutions to the problems. Open ended problems when assigned; students may be encouraged to work in library to refer to various print resources to generate alternate solutions to those problems.

- Teaching and research should go hand in hand. The research in the subject needs to be integrated into classroom teaching either by asking students to locate relevant literature in journals, read and analyze the research findings or the teachers themselves may share research findings. This will help the students to understand the current status of research, know the various alternatives available to solve a problem, and identify gaps, as well as motivate them to undertake research.

- A system of continuous evaluation of students' performance based upon a variety of techniques of assessment should be designed and implemented to assess student performance in technical knowledge and skills, soft skills and managerial skills and generate seriousness among students as well as to increase the validity and reliability of evaluation.

- In case of component design, structural design and system design, open book examination needs to be introduced. This will help the students in acquiring in-depth knowledge in the subject, minimize rote learning and also help them to apply the learnt knowledge.

5.2.3 Strategies for Hearts on

- Subjects like Science and Humanism can be included to sensitize the students towards the needs of society and the role science can play in meeting those needs.

- During the summer vacations/winter vacations students should be encouraged to take up surveys of the community to identify the community related problems and the community projects can be undertaken by group of students to improve the quality of life of people. The students of technical institutions can organize training/awareness camps for community.

- Social service activities can also be undertaken under the scheme of NSS/NCC etc.

\section{Strategies for Enhancing Industry Participation in Curriculum \& Instructional Processes}

The following strategies can be used to enhance and ensure industry involvement in curriculum and instructional processes [14]:

\subsection{Industry participation in curriculum design}

- Mandatory representation of industry on Board of Studies for various Programmes: Curricula of various programmes need to reflect the needs of industry and thus Board of Studies(BOS) constituted for designing of curricula of various programmes should have mandatory representation of industry. The industry selected for the purpose must be one which is showing high performance, using modernized processes and technology and current in its practices and processes .related to management, manufacturing etc. For example, reputed institutions such as PSG College of Technology, Coimbtore and Walchand Institute of Technology, Solapur have adequate representation of industry on its BOS [15]. Institute of Technical Education, Singapore, one of the leading institutions, has intensive involvement of industry such as Association of Singapore Marine industries and other stakeholders in its curriculum development process.

- Manpower Spectrum Studies and Competence Profiles: Industrial associations must take the lead in undertaking manpower spectrum studies and identify the competence profile of engineers at various levels and across the various departments of the industry. Such studies can form the basis of designing and developing the curricula for various programmes.

- Technology Forecasting Committees: Technology is fast changing and the curricula must keep pace with the changing technology. This requires that technological changes that are likely to take place in the coming four to five years are forecasted and integrated into the curriculum of various courses so as to ensure that students who graduate after four years are proficient in handling the current technology. Technology forecasting committees comprising of technologists and academicians be constituted for various disciplines.

- Employer's Feedback: A mechanism need to be instituted to obtain employer's feedback regarding 
the performance of passouts in order to introduce changes in curricum .

- Alumni Feedback Mechanism: Feedback from the alumni working in industry can be of potential use in bringing changes in the curriculum. Formal and informal feedback from the alumni must be obtained to introduce changes in the processes.

6.2 Industry involvement in Instructional Processes

- Industry-Academia Exchange Programmes: The exchange programmes can help in providing needed industrial exposure to faculty and also help the students to get practical knowledge from the industry personnel. Faculty may be encouraged to serve the industry for two to three months every two years.

- Companies offering Electives to Students: Companies can offer electives to students. For example, Infosys offers courses in Business Intelligence, Enterprise Resource Planning and Mobile Application Development in Sona College of Technology, Bengaluru[14]. This kind of arrangement will help students to acquire knowledge and skills in specialized areas.

- Inviting Persons Working at Shop floor for Demonstrations:Persons working at the shop floor in the industry can also be invited to give demonstrations on the latest machinery and equipment to the students. This will help the faculty, technical staff and the students to learn from and skilled persons and hone their skills.

- Joint Supervision and Evaluation of Project Work and Industrial Training:Students undertaking industrial problems as their project work need to be jointly supervised and evaluated by the industry personnel and faculty. Likewise, industry personnel needs to be involved in evaluation of industrial training.

- Collaborative Research Projects: Industry academia needs to join hands for taking up joint research projects in order to find solutions to the problems faced by industry or society and to promote transfer of knowledge among partners and strengthening inter-sectoral and interdisciplinary research. Collaborative research undertaken by the Solid and Structural Mechanical Group at University of Trento in collaboration with SACMI, world leader industry for Ceramics and ENGINSOFT, a medium enterprise specialized in Virtual prototyping for improving the ceramic production process and developing novel multi functional materials and structures lend support to the argument [16].
- Expert Lectures and Seminars by Industry Personnel: Technical institutions must create a pool of expertise available in the near by industry relevant to the programmes being offered. The industry personnel may be invited frequently to interact with faculty and students on the current practices.

The strategies suggested above if implemented in technical education system can improve the quality of curriculum and instructional processes and in turn will enhance the employability of the graduates.

\section{References}

[1] Manpower Group. '2013 Talent Shortage Survey: research Results', 2013. www. Manpower.com

[2] AICTE.'AICTE Approval Handbook', New Delhi:All India Council for Technical Education. 2013.

[3] Aspiring Minds Pvt. Ltd. 'National Employability Study IT/ITeS Sector: Key findings and Intervention Indicators', Aspiring Minds Assessment Pvt. Ltd. 2010.

[4] V K Gokuladas. 'Predictors of employability of engineering graduates in campus recruitment drives of Indian software services companies', International Journal of Selection \& Assessment, 19(3)pp.313-3192011.

www.emeraldinsight.com/bibliographic databases.htm?id=1952742

[5] V. K. Gokuladas. 'Technical and non-technical education and the employability of engineering graduates: an Indian case study', International Journal of Training and Development, 14(2).pp. 130-143, June 2010.

[6] Andreas Blom and Hiroshi Saeki. 'Employability and Skill Set of Newly Graduated Engineers in India', The World Bank South Asia Region Education Team. 2011.

[7] UK Commission for Employment and Skills 'Employability Skills Project: Review of Evidence on Best Practice in Teaching and Assessing Employability Skills', Policy Research Institute. 2008

[8] Penn State University. Electrical Engineering Curriculum Changes for 2012 . http://www.ee.psu.edu/Undergraduate/2012EEc urriculumchange.pdf, 2014.

[9] K.C. Gonzalez. 'Changes in UTSA engineering curriculum improve student retention, grades, 
graduation rate', UTSA Today.2014. http://www.utsa.edu/todav/2014/01/iustintime.html

[10] Ernest G. Frankel. Changes in Engineering Education, MIT Faculty Newsletter, XX(5), 2008.

web.mit.edu/fnl/volume/205/frankel.Html

[11] Noubar Afeyan. 'The top 10 Emerging Technologies for 2014', The World Economic Forum Blog. forumblog.org/2014/02/top-tenemerging-technologies-2014.

[12] P. K. Tulsi and M. P. Poonia. 'Creating Enabling Environment in technical Institutions for Hands On , Minds On and Hearts On', Journal of Engineering and Technology Education, 6(2), 2012.

[13] APEC. 'Case study of an Institute of Technical
Education (ITE) Singapore', Asia Pacific Economic Cooperation(APEC). 2010.

[14] P.K. Tulsi and M.P.Poonia. 'Participation of Industry in Curriculum Design and Instructional', Unpublished Paper. 2013

[15] ACCA. 'AICTE- CII Survey of Industry-Linked Te chnical Institutes', 2013 . https://www.mvcii.in/KmResourceApplication/ 36287.AICTECIITISUrvev13F.odf

[16] F.Bosi, E. Mazzohcci, I. Jatro, F. Dal Corso, A. Piccolroaz, L. Desri, D. Bigoni, A. Cocquio, M. Cova, and S. Odorizzi. 'A Collaborative Project between Industry and Academia to Enhance Engineering Education at Graduate and $\mathrm{PhD}$ Level in Ceramics', International Journal of Engineering Education, 27(6), pp1362-1376. 2013. 